\title{
(2) OPEN ACCESS \\ Objectively measured near work, outdoor exposure and myopia in children
}

\author{
Longbo Wen, ${ }^{1}$ Yingpin Cao, ${ }^{1}$ Qian Cheng, ${ }^{2}$ Xiaoning Li, ${ }^{1,3}$ Lun Pan, ${ }^{1,3}$ Lei Li, ${ }^{2}$ \\ HaoGang Zhu, Weizhong Lan, ${ }^{1,3}$ Zhikuan Yang
}

${ }^{1}$ Aier School of Ophthalmology, Central South University, Changsha, Hunan, China ${ }^{2}$ State Key Laboratory of Software Development Environment, Beihang University, Beijing, China ${ }^{3}$ Aier School of Optometry and Vision Science, Hubei University of Science and Technology, Xianning, Hubei, China

\section{Correspondence to}

Professor Zhikuan Yang, Aier School of Ophthalmology,

Central South University, Changsha, Hunan, China; 13380071988@189.cn;

Weizhong Lan;

lanweizhong@aierchina.com

Received 18 September 2019 Revised 5 January 2020 Accepted 30 January 2020
Check for updates

(C) Author(s) (or their employer(s)) 2020. Re-use permitted under CC BY-NC No commercial re-use. See rights and permissions. Published by BMJ.

To cite: Wen L, Cao Y, Cheng $\mathrm{Q}$, et al. Br J

Ophthalmol

2020;104:1542-1547.

\section{ABSTRACT}

Aim To reassess the association between near work, outdoor exposure and myopia in children through an objective approach.

Methods Eighty-six children (10.13 \pm 0.48 years) were asked to wear Clouclip, a newly developed wearable device that is able to measure working distance and eyelevel illuminance, for a complete week to obtain information on near work and outdoor exposure. The mean daily Clouclip wearing time was $11.72 \pm 1.14$ hour. The spherical equivalent refraction was determined by cycloplegic autorefraction.

Results The myopic children were found to be exposed to light intensities $>3000$ lux $(0.68 \pm 0.50$ hour vs 1.02 \pm 0.53 hour, $\mathrm{p}=0.012)$ and $>5000$ lux $(0.42 \pm 0.35$ hour vs $0.63 \pm 0.31$ hour, $p=0.004$ ) for shorter durations on average each day than the non-myopic children. Additionally, the myopic children spent more time on average each day on activities at a distance of $<20 \mathrm{~cm}$ than non-myopic children $(1.89 \pm 0.61$ hour vs 1.52 \pm 0.77 hour, $p=0.019$ ). In the multivariate logistic analysis, the time spent with a higher light intensity ( $>3000$ lux (OR=0.27, 95\% Cl: 0.10 to $0.72, p=0.009$ ); $>5000$ lux (OR=0.11, 95\% Cl: 0.02 to $0.56, p=0.008)$ ) and a working distance of $<20 \mathrm{~cm}$ (in a circumstance of $>3000$ lux (OR=1.17, 95\% Cl: 1.09 to $1.86, p=0.038$ ) or in that of $>5000$ lux $(\mathrm{OR}=1.12,95 \% \mathrm{Cl}: 1.03$ to 1.77 , $p=0.046)$ ) were the independent protective factors and risk factors, respectively.

Conclusion The current study provides novel evidence, based on objective data, to support the association between the intensity of near work, light intensity and myopia. However, the causality and the dose-effect relationship need to be investigated further.

\section{INTRODUCTION}

Myopia is generally thought to be caused by both genetic and environmental factors. Given the rapid increase in myopia prevalence in the past decades, environmental factors clearly play an important role in the development of myopia. ${ }^{1}$ Near work and the time spent outdoors are the two most studied environmental factors related to myopia.

Although studies investigating the relationship between near work and myopia have been conducted centuries ago, the findings from them have been controversial. ${ }^{2}$ This controversy may be related to the differences in study designs, definitions of myopia and the quantitative metrics of near work. ${ }^{3}$ However, the most important reason for the controversy is the method used to quantify near work. Questionnaires, for example, have been doubted for their reliability in terms of accuracy. ${ }^{4} 5$ Therefore, to address this question, a real-time, objective approach to quantify near work must be developed first. In fact, a recent study showed that the time spent on near-work activities that was estimated by the questionnaire tended to be overestimated compared with that recorded by an objective device RangeLife. ${ }^{6}$

Compared with the relationship between near work and myopia, the relationship between the time spent outdoors and myopia is relatively well accepted. A number of studies have reported a correlation between an increased amount of time spent outdoors and a lower risk for myopia development. ${ }^{78}$ In addition, the treatment effect against myopia onset has been demonstrated in several school-based trials. ${ }^{9-11}$ Since bright light has been found to be an independent protective agent to inhibit myopia onset in chicks, ${ }^{12} 13$ monkeys ${ }^{14} 15$ and humans, ${ }^{16}$ exposure to bright light outdoors seems to be the critical reason for the efficacy of outdoor activities. A question following this implication is whether a dose-effect relationship exists between light intensity and treatment efficacy or whether at least a specific threshold of light intensity influences the treatment effect. Obviously, measuring the exposure of bright light in a quantitative manner is required to answer this question. In light of this, a number of devices have been applied in recent years, including wristwatch-like devices, such as Actiwatch ${ }^{17}$ and Fitsight, ${ }^{18}$ and devices worn on clothes, such as HOBO. ${ }^{9}$ However, the illuminance obtained by these devices does not match the level perceived by the eye.

The Clouclip device was first developed to be attached to spectacle arms, and it uses an infrared sensor to give a warning signal when the head position is too close to a desk or book while reading. In its research configuration, it measures distance to the nearest surface along the line of sight and collects information on light intensity along the line of sight. In brief, the infrared distance sensor emits a beam of infrared light, which reflects after irradiating the object. Then, the sensor receives the reflected signal, uses the charge-coupled device image to process the time difference between the transmission and reception data and calculates the distance. The light intensity sensor converts light intensities to voltage values to calculate the illuminance. Our previous study showed that Clouclip has 

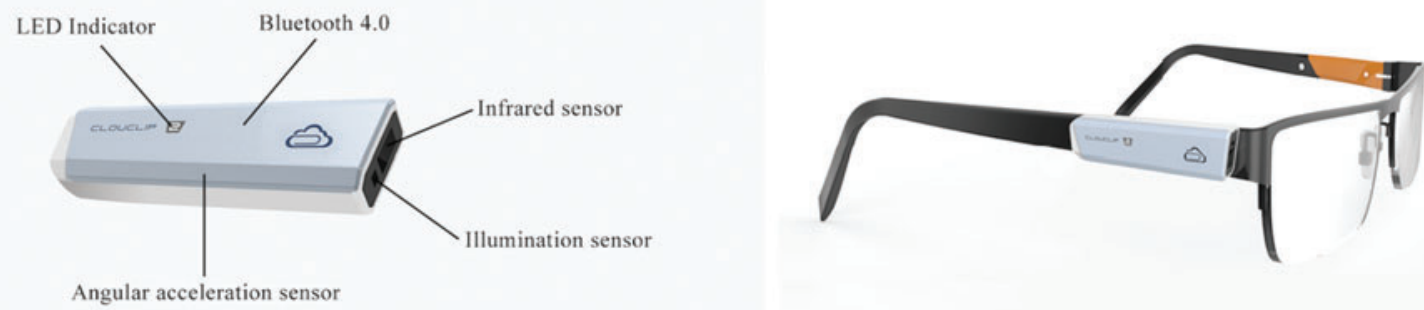

Size: $45.3 \mathrm{~mm} \times 13.4 \mathrm{~mm} \times 8.0 \mathrm{~mm}$

Figure 1 The Clouclip device. Locations of the sensors in the Clouclip device (A) and Clouclip attached to the right arm of a spectacle frame (B).

high accuracy and good repeatability for measuring the working distance and ambient light intensity. ${ }^{19}$

Considering this advantage, we used Clouclip to collect near work and outdoor activity data and analyse the environmental risk factors to which myopic and non-myopic children are typically exposed, and we aimed to illustrate the relationship between these risk factors and the children's refractive status.

\section{METHODS}

Participants for this study were recruited from a group of fifth grade students at Lao Liangcang Primary School; the school is located in Ningxiang, a county-level city that is located near Changsha, has a population of approximately 1.4 million and is located in Hunan Province in central China. All participants underwent a comprehensive ocular examination, including an ocular health assessment and cycloplegic autorefraction. Cycloplegia was induced with three cycles of cyclopentolate 1\% (one drop) instilled 5 min apart. The cycloplegic status was then evaluated by testing the light reflex $30 \mathrm{~min}$ after the last administration of cyclopentolate. An autorefractor (model AR-1, Nidek, Aichi, Japan) was used to perform the autorefraction. A spherical equivalent refraction was calculated as sphere power $+1 / 2$ cylinder power. Only participants with normal ocular health and a spherical equivalent refractive error between $-6.00 \mathrm{D}$ and $+1.00 \mathrm{D}$ and anisometropia of $<1.00 \mathrm{D}$ were included in the study.

After the study was explained and before the examination, written consent was obtained from the students and their parents. The study complied with the tenets of the Helsinki Declaration.

The Clouclip device (Glasson Technology Co Ltd, Hangzhou, China) has a built-in infrared distance sensor (measurement range: 15 to $60 \mathrm{~cm}$ ) and a light intensity sensor (measurement range: 1 to 655336 lux) for detecting the working distance and ambient light intensity in real time (figure 1 ). The field of view of the infrared distance sensor is 25 degrees. Clouclip is also equipped with a three-axis accelerometer ( $\mathrm{X}, \mathrm{Y}$ and $\mathrm{Z}$ axes). If the triaxial accelerometer does not detect any change for more than $40 \mathrm{~s}$, the Clouclip enters 'sleep mode', and no data are recorded. Clouclip is otherwise programmed to measure the working distance every $5 \mathrm{~s}$ and ambient illuminance every 120 s. It is worn on the right arm of an eyeglass frame to measure the viewing distance and eye-level illuminance along the line of sight. For the individuals who did not wear spectacles, frames without lenses were provided so that Clouclip could be fitted. The participants were required to wear Clouclip throughout the day, except during bathing and sleeping, continuously for 1 week (including 5 weekdays and 2 weekend days) and were encouraged to perform their daily activities as usual during the week. To improve compliance, teachers and parents were asked to check whether the participants were wearing the devices every day at school or at home.

Following the week during which the participants wore the device, all raw data, including working distance, eye-level illuminance and the corresponding data collection time points, were downloaded from the cloud platform. The data collected between 07:00 a.m. and 20:00 p.m. were used in the study, as this period encompassed the times during the day at which the vast majority of light exposure and near work occurred for all subjects. Furthermore, only data obtained from at least $80 \%$ of the total required wearing time during the day were considered valid. A valid data set for a subject was identified as a data set that spanned a valid period of time, which included at least 3 days during the week and at least 1 day during the weekend.

To conduct a comprehensive evaluation of near work and light exposure and their effects on refractive error, different metrics based on the viewing distance and light intensity were calculated. For near work, the following parameters were calculated: (1) average daily near-work distance, which was the mean of the viewing distances for each day; (2) average daily frequency of continuous near work, which was defined as near work that lasted continuously for more than $30 \mathrm{~min}$ with an interruption of $<60 \mathrm{~s}$ (ie, the time spent at a distance between periods of near work was $<60$ s) and (3) average daily time of exposure to a viewing distance under various distance thresholds $(<60 \mathrm{~cm}$, $<50 \mathrm{~cm},<40 \mathrm{~cm},<30 \mathrm{~cm},<20 \mathrm{~cm})$. For light exposure, the following metrics were included: (1) average daily light intensity, (2) average daily time of exposure to bright light above various intensity thresholds (>1000 lux, >2000 lux, >3000 lux, >5000 lux) and (3) average daily frequency of outdoor exposure, that is, the number of transitions between indoor $(<1000$ lux $)$ and outdoor ( $\geq 1000$ lux) exposure. In addition, the time distribution of the average light intensity and average near work distance per 2 min was also analysed to compare the difference in the temporal patterns of these two metrics between the myopic and nonmyopic children.

\section{Statistical analysis}

A t-test with two independent samples for quantitative variables or a $\chi^{2}$ test for categorical variables was conducted to compare the differences in potential factors associated with myopia between 
A

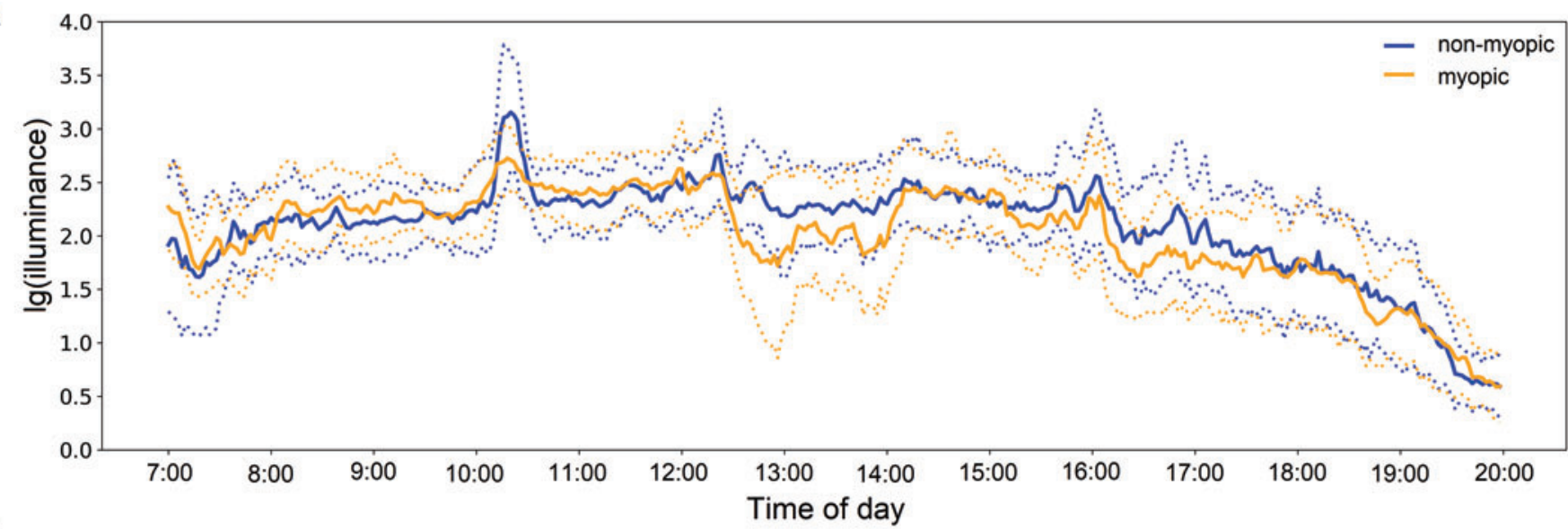

B

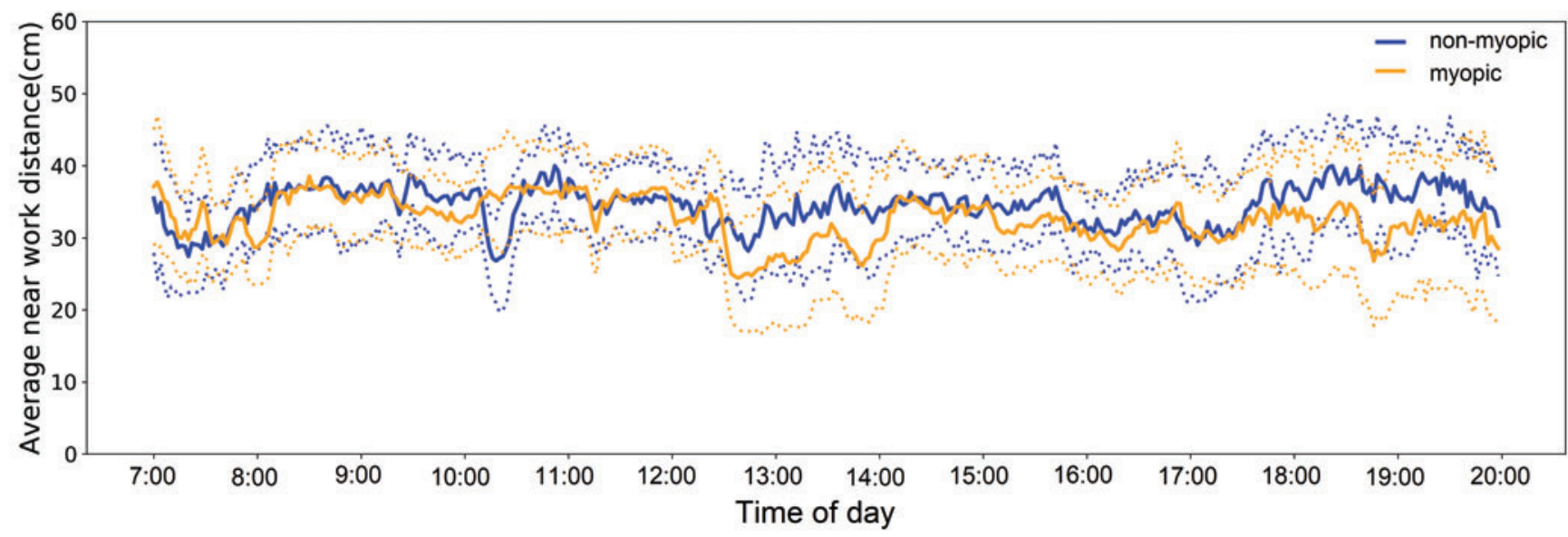

Figure 2 Temporal patterns of light exposure (A) and near-work activities between the non-myopic and myopic children (B). The light exposure data was plotted on a log scale. Significantly different levels of light intensity experienced by the two groups were observed in the periods of 10:10 a.m. $\sim$ 10:30 a.m., 12:20 p.m. 14:10 p.m. and 16:00 p.m. 17:30 p.m. Significantly different levels of near-work distance were also noted in the periods of 10:10 a.m. 10:30 a.m., 12:30 p.m. 14:00 p.m. and 17:30 p.m. 20:00 p.m.

the myopic and non-myopic children. A logistic regression was constructed with myopia as the binary outcome variable. The explanatory variables included age, sex, parental myopia history, average daily time spent within a working distance of $<20 \mathrm{~cm}$, average daily near work distance and average daily time spent with a light intensity of $>3000$ or $>5000$ lux. The interaction of the two explanatory variables was accounted for in the logistic regression. Statistical analyses were performed using SPSS 25.0 (SPSS Inc, Chicago, Illinois). The cut-off value for statistical significance was set at a two-tailed $\mathrm{p}$ value of $<0.05$.

\section{RESULTS}

A total of 86 fifth grade students with a mean age of $10.13 \pm 0.48$ years were included in the study, of whom 42 (48.84\%) were boys and $44(51.16 \%)$ were girls. All participants underwent a cycloplegic autorefraction, and the mean spherical equivalent refraction (SER) was $-0.35 \pm 1.26$ D. Among all subjects, $32.56 \%(28 / 86)$ were myopic, which was defined as an SER $\leq-0.50 \mathrm{D}$. Overall, the compliance of all participants in terms of wearing Clouclip was satisfactory. Specifically, the mean valid weekdays were $3.98 \pm 0.36 \mathrm{~d}$ and the mean valid weekend days were $1.13 \pm 0.11 \mathrm{~d}$. Furthermore, the mean daily Clouclip wearing time was $11.72 \pm 1.14$ hour.

The temporal patterns of light exposure and near-work activities are shown in figure 2. Overall, the non-myopic and myopic children showed similar temporal patterns for these two environmental factors. However, there were some episodes in which varied exposure to these environmental factors between the two groups was observed. For instance, the light intensity experienced by the non-myopic children was significantly greater than that experienced by the myopic childrenbetween 10:10 a.m. and 10:30 a.m. (2992.17 \pm 482.46 lux vs $1490.34 \pm 349.57$ lux, $\mathrm{p}<0.001$ ), between 12:20 p.m. and 14:10 p.m. (1366.28 \pm 211.42 lux vs $815.61 \pm 129.37$ lux, $\mathrm{p}<0.001$ ), and between 16:00 p.m. and 17:30 p.m. (1215.92 \pm 177.13 lux vs 756.11 \pm 114.90 lux, $\mathrm{p}<0.001$ ). For near work, the non-myopic children exhibited significantly longer viewing distances than the myopic children between $12: 30$ p.m. and 14:00 p.m. $(33.25 \pm 2.89 \mathrm{~cm}$ vs $26.54 \pm 1.73 \mathrm{~cm}, \mathrm{p}=0.008)$ and between 17:30 p.m. and 20:00 p.m. $(34.93 \pm 3.16 \mathrm{~cm}$ vs $28.99 \pm 1.81 \mathrm{~cm}, \mathrm{p}=0.001)$. However, it was noted that between 10:10 am and 10:30 am, the non-myopic children showed a significantly shorter viewing distance than the myopic children.

Table 1 shows the difference in the potential factors potentially associated with myopia between the myopic and non-myopic children. There was no difference in the average daily exposure duration with light intensity intensities of $>1000$ lux and 2000 lux between the myopic children $(1.67 \pm 0.70$ hour, 0.97 \pm 0.68 hour $)$ and the non-myopic children $(1.98 \pm 0.93,1.19$ \pm 0.65 hour $)(p=0.132, p=0.067)$. However, the myopic children were exposed to light intensities of $>3000$ lux and $>5000$ lux for shorter durations than were the non-myopic children. The 
Table 1 Comparison of the factors potentially associated with myopia between myopic and non-myopic children

\begin{tabular}{|c|c|c|c|}
\hline & Myopic ( $\leq-0.5 \mathrm{D}, \mathrm{n}=28$ ) & Non-myopic (>-0.5D, $n=58)$ & $P$ values \\
\hline Age (years) & $10.10 \pm 0.56$ & $10.14 \pm 0.44$ & 0.712 \\
\hline Males (n, \%) & $13(46.4 \%)$ & $29(50.0 \%)$ & 0.756 \\
\hline Females $(n, \%)$ & $15(53.6 \%)$ & $29(50.0 \%)$ & \\
\hline No myopic parents $(n, \%)$ & $18(64.3 \%)$ & $37(63.8 \%)$ & 0.964 \\
\hline One or two myopic parents ( $\mathrm{n}, \%)$ & $10(35.7 \%)$ & $21(36.2 \%)$ & \\
\hline Average daily light intensity (lux) & $739.40 \pm 429.13$ & $831.70 \pm 440.02$ & 0.054 \\
\hline Average daily time spent with a light intensity of $>1000$ lux (h) & $1.67 \pm 0.70$ & $1.98 \pm 0.93$ & 0.132 \\
\hline Average daily time spent with a light intensity of $>2000$ lux (h) & $0.97 \pm 0.68$ & $1.19 \pm 0.65$ & 0.067 \\
\hline Average daily time spent with a light intensity of $>3000$ lux (h) & $0.68 \pm 0.50$ & $1.02 \pm 0.53$ & $0.012^{*}$ \\
\hline Average daily time spent with a light intensity of $>5000$ lux (h) & $0.42 \pm 0.35$ & $0.63 \pm 0.31$ & $0.004^{*}$ \\
\hline Average daily frequency of outdoor exposure & $7.22 \pm 1.53$ & $8.31 \pm 1.71$ & 0.074 \\
\hline Average daily time spent within a working distance of $<60 \mathrm{~cm}$ (h) & $5.12 \pm 1.97$ & $6.06 \pm 2.28$ & 0.063 \\
\hline Average daily time spent within a working distance of $<50 \mathrm{~cm}$ (h) & $4.61 \pm 1.75$ & $5.28 \pm 1.97$ & 0.109 \\
\hline Average daily time spent within a working distance of $<40 \mathrm{~cm}$ (h) & $3.70 \pm 1.50$ & $4.02 \pm 1.64$ & 0.371 \\
\hline Average daily time spent within a working distance of $<30 \mathrm{~cm}$ (h) & $3.06 \pm 1.30$ & $2.92 \pm 1.20$ & 0.692 \\
\hline Average daily time spent within a working distance of $<20 \mathrm{~cm}$ (h) & $1.89 \pm 0.61$ & $1.52 \pm 0.77$ & $0.019^{*}$ \\
\hline Average daily near work distance $(\mathrm{cm})$ & $31.24 \pm 4.85$ & $33.86 \pm 3.37$ & $0.011^{*}$ \\
\hline Average daily frequency of continuous near work & $1.98 \pm 1.26$ & $2.16 \pm 1.22$ & 0.364 \\
\hline
\end{tabular}

Note: The asterisks indicate statistical significance.

average differences in the durations were 0.34 hour $(\mathrm{p}=0.012)$ and 0.21 hour $(p=0.004)$, respectively. Additionally, the myopic children spent more time on activities within a working distance of $20 \mathrm{~cm}$ than the non-myopic children did $(1.89 \pm 0.61$ hour vs $1.52 \pm 0.77$ hour, $\mathrm{p}=0.019)$. The myopic children also performed near work at a shorter distance than the non-myopic children did $(31.24 \pm 4.85 \mathrm{~cm}$ vs $33.86 \pm 3.37 \mathrm{~cm}, \mathrm{p}=0.011)$. Nevertheless, no significant difference between the myopic and non-myopic children was found in the age, sex, parental myopia history, light intensity, time spent with a light intensity of $>1000$ lux, time spent with a working distance of $>30 \mathrm{~cm}$ and average frequency of continuous near work and outdoor exposure.

To further clarify which factors are independently associated with myopia, a logistic regression was performed after adjusting for age, sex and parental myopia history. As shown in table 2, the time spent with a light intensity of $>3000$ lux was protective against myopia $(\mathrm{OR}=0.27,95 \% \mathrm{CI}$ : 0.10 to $0.72, \mathrm{p}=0.009)$. According to another independent analysis (table 3), the time spent with a light intensity of $>5000$ lux was also found to be

Table 2 Logistic regression of the factors potentially associated with myopic or non-myopic students when the threshold of exposure to light intensity was set at 3000 lux

\begin{tabular}{llllll}
\hline & & \multicolumn{3}{l}{$95 \% \mathrm{Cl}$} & \\
\cline { 3 - 5 } Variables & OR & Lower & Upper & P values \\
\hline Age & 0.94 & 0.61 & 1.17 & 0.152 \\
Sex & 1.15 & 0.72 & 2.04 & 0.223 \\
\hline Parental myopia history & 1.24 & 0.81 & 1.99 & 0.106 \\
$\begin{array}{llllll}\text { Average daily time spent within a working } \\
\text { distance of }<20 \mathrm{~cm}(\mathrm{~h})\end{array}$ & 1.17 & 1.09 & 1.86 & $0.038^{*}$ \\
Average daily near work distance $(\mathrm{cm})$ & 0.95 & 0.31 & 1.94 & 0.104 \\
$\begin{array}{l}\text { Average daily time spent with a light intensity of } \\
>3000 \text { lux (h) }\end{array}$ & 0.27 & 0.10 & 0.72 & $0.009^{*}$ \\
Cox and Snell $\mathrm{R}^{2}$ & 0.084 & & & \\
\hline
\end{tabular}

Note: The asterisks indicate statistical significance. a protective factor for myopia $(\mathrm{OR}=0.11,95 \% \mathrm{CI}: 0.02$ to 0.56 , $\mathrm{p}=0.008)$. In contrast, the time spent within a working distance of $<20 \mathrm{~cm}$ was found to be a risk factor for myopia $(\mathrm{OR}=1.17$, 95\% CI: 1.09 to $1.86, \mathrm{p}=0.038$; OR $=1.12$, 95\% CI: 1.03 to $1.77, \mathrm{p}=0.046)$ at both thresholds of light intensity included in the regression model.

\section{DISCUSSION}

This is the first study to explore the relationships between light exposure, near work and myopia through objectively measured data. It was found that the time spent with a light intensity of $>3000$ lux was a protective factor for myopia, while the time spent within a working distance of $<20 \mathrm{~cm}$ was a risk factor for myopia.

Whether there is an association between near work activities and myopia has been debated for centuries. ${ }^{2}$ Huang et al summarised 15 cross-sectional and 12 longitudinal studies published between 1989 and 2014 in a systematic review. ${ }^{3}$ Among all these studies, only 10 cross-sectional and 4 longitudinal studies

Table 3 Logistic regression of the factors potentially associated with myopic or non-myopic students when the threshold of exposure to light intensity was set at 5000 lux

\begin{tabular}{|c|c|c|c|c|}
\hline \multirow[b]{2}{*}{ Variables } & \multirow[b]{2}{*}{ OR } & \multicolumn{2}{|l|}{$95 \% \mathrm{Cl}$} & \multirow[b]{2}{*}{ P values } \\
\hline & & Lower & Upper & \\
\hline Age & 0.97 & 0.73 & 1.09 & 0.113 \\
\hline Sex & 1.31 & 0.69 & 2.25 & 0.273 \\
\hline Parental myopia history & 1.09 & 0.63 & 1.95 & 0.138 \\
\hline $\begin{array}{l}\text { Average daily time spent within a working } \\
\text { distance of }<20 \mathrm{~cm}(\mathrm{~h})\end{array}$ & 1.12 & 1.03 & 1.77 & $0.046^{*}$ \\
\hline Average daily near work distance $(\mathrm{cm})$ & 0.99 & 0.74 & 1.65 & 0.122 \\
\hline $\begin{array}{l}\text { Average daily time spent with a light } \\
\text { intensity of }>5000 \text { lux (h) }\end{array}$ & 0.11 & 0.02 & 0.56 & $0.008^{*}$ \\
\hline Cox and Snell $R^{2}$ & 0.097 & & & \\
\hline
\end{tabular}

Note: The asterisks indicate statistical significance. 
suggested an association between near work and the incidence or progression of myopia, while the others did not. One reason for the inconsistency across these studies was the varied 'parameter' that was used to quantify near work, although a questionnaire or diary was the most commonly used method. Conventionally, near work activities have been quantified only by the duration. Later, accommodation-weighted measures (ie, dioptre-hours) were proposed for the assessment of near work. ${ }^{20}$ However, more recently, the duration of near work activities that occur only within a certain distance has been considered a more robust indicator of myopiogenic effects. For instance, Quek et al found that the risk of myopia increased by $80 \%$ for the subjects who engaged frequently in reading at a close distance $(<30 \mathrm{~cm}) \mathrm{com}-$ pared with that for subjects who never engaged in reading within this distance. ${ }^{21}$ Similarly, Ip et al reported that a close reading distance $(<30 \mathrm{~cm})$ independently increased the odds of having myopia in children by $250 \% .^{22}$ The results from the Anyang Childhood Eye Study also showed that a close reading distance, defined by a different threshold $(\leq 20 \mathrm{~cm})$, was significantly associated with a longer axial length. ${ }^{23}$ However, these reported near-work distances were questionnaire-based and therefore could only provide ambiguous thresholds for the 'risk' zone of near-work activities. In contrast, here, we used Clouclip to record the working distance objectively in real time to clarify the issue. Consistent with previous studies, the time spent at a close working distance $(<20 \mathrm{~cm})$ was found to be associated with myopia, further suggesting that only near work activities that occur within a certain distance are an important risk factor for myopia.

Prior to the development of Clouclip, several previous studies attempted to quantify outdoor activities, or more precisely, the ambient illuminance, by other wearable devices. Read et al adopted Actiwatch to measure light intensity. ${ }^{17}$ The authors found that more daily light exposure and more time exposed to light levels of $>3000$ lux per day were significantly associated with less axial eye growth. Additionally, in a clinical trial investigating the anti-myopia effect by promoting outdoor activities, Wu et al used another wearable device, HOBO, to measure light intensity. ${ }^{9}$ The authors reported that an increase in exposure time to $70 \mathrm{~min}$ per week to a light intensity of approximately $>1000$ lux can reduce the risk of myopia development by $35 \%$. The current study also confirmed the presence of a negative association between the duration of elevated light intensity and myopia (ie, a longer exposure time to an elevated light intensity is correlated with a non-myopic status), but this association only existed when the cut-off value of the elevated light intensity was set to 3000 lux or higher. Although the threshold of effective light intensity seems to have been varied between these studies, it is rather difficult to compare the values directly due to the different study designs and devices used in these studies. HOBO is generally worn on the shirt (collar or chest) ${ }^{24}$ with the light sensor facing outward. Actiwatch is a wrist-worn device ${ }^{25}$ whose direction of measurement depends on the wrist positioning. However, as mentioned earlier, the Clouclip is a spectacle-mounted device that measures light exposure along the line of sight. Very recently, another spectaclemounted device, RangeLife, was developed, but the related report was very limited. ${ }^{6}$ A future investigation of the impact of the measurement position and angle may facilitate the comparison of the values acquired from these devices across other studies.

In the current study, we also sought to compare the temporal patterns of light exposure and near-work activities between these two groups of subjects. Despite an overall similar pattern, these two groups showed varied patterns of exposure to these environmental factors in some specific episodes. The episode from 12:20 p.m. to $14: 10$ p.m. corresponded to when the children had afternoon self-study. It seems that the non-myopic children tended to go outdoors, while the myopic chidlren more likely to stay in the classroom to study during this period. Another episode from 16:00 p.m. to 17:30 p.m. corresponded to when the children left school. A plausible assumption might be that the non-myopic children walk home, while their myopic peers ride in a vehicle, in which the ambient illuminance is usually much lower than that of outdoor environments. The largest difference in light intensity experienced was observed between 10:10 a.m. and 10:30 a.m., which corresponded to the time for outdoor physical exercise during class recess. This finding further supports the assumption that nonmyopic children spend more time outdoors than their peers. In contrast, the myopic children exhibited significantly shorter viewing distances than the non-myopic children in two typical episodes during which they completed assignments (from 12:30 p.m. to 14:00 p.m. and from 17:30 p.m. to 20:00 p.m.), indicating that these two groups of subjects demonstrate different postures when reading and writing. It was surprising that during class recess for outdoor physical exercise (between 10:10 a.m. and 10:30 a.m.), in which the non-myopic children experienced much higher light intensities than their myopic peers, the non-myopic children showed significantly shorter viewing distances than the myopic children did. Nevertheless, an additional analysis revealed that during this period, only $8.62 \%(5 / 58)$ of the non-myopic children were actually engaged in near-work activities, while 50\% of (14/ 28) of the myopic children were engaged in near-work activities. Therefore, it is understandable that the non-myopic children experienced higher light intensities while simultaneously showing closer viewing distances.

The thresholds of these two major environmental factors may help provide relevant references for environmental modifications with regard to myopia control. Nevertheless, the specific level of these risk factors should not be over-extrapolated, considering the limitations of the study. First, although the study covered the activities performed on both weekdays and weekend days and the students' schedules of activities tended to be relatively regular, the Clouclip device was worn for only 1 week, which might not fully represent the visual behaviour of the subjects. Second, the relatively small sample size in the current study may not be sufficient to accurately assess the quantitative relationship between environmental factors and refractive error. Third, since the habitual near work distance is correlated with body height and the exposed level of light intensity also relies on the latitude of the study site, future studies in other populations are warranted. Last but not least, given the nature of the cross-sectional design of the study, we recommend that these findings are further confirmed by prospective studies.

In conclusion, by measuring near-work intensity and light-level illuminance with Clouclip, the association between these environmental factors and myopia was confirmed. However, the causality and the dose-effect relationship need to be investigated further.

Correction notice This article has been updated since it was published online. WL and $Z Y$ are joint corresponding authors.

Acknowledgements The Clouclip devices were developed and provided by Glasson Technology Co, Ltd, Hangzhou, China. The sponsor is acknowledged for kindly providing the key devices, the Clouclip devices. However, the sponsor had no role in the design and execution of the study; the collection, management, analysis and interpretation of the data; the preparation, review and approval of the manuscript or the decision to submit the manuscript for publication.

Contributors $L W, W L$ and $Z Y$ designed the research. $L W$ and $Y C$ conducted the study. LW, YC and XL collected the data. QC, LP, LL and HZ analysed the data. LW wrote the manuscritpt. LW, WL and ZY critically revised the manuscript. All authors discussed the results and commented on the manuscript. 
Funding The study was supported by the Fundamental Research Funds for the Central Universities of Central South University (2019zzts367), the Science Fund for Distinguished Young Scientists from the Hunan Provincial Science and Technology Department (2019JJ20034) and the key Research and Development Programme of Hunan Province (2019SK2051).

Competing interests None declared.

Patient consent for publication Parental/guardian consent obtained.

Ethics approval The study was approved by the Aier Eye Hospital Group Ethics Committee (No. IRB2016004).

Provenance and peer review Not commissioned; externally peer reviewed.

Data availability statement Data are available upon request. The data used to support the findings of this study are available from the corresponding author (Weizhong Lan, Zhikuan Yang) upon request.

Open access This is an open access article distributed in accordance with the Creative Commons Attribution Non Commercial (CC BY-NC 4.0) license, which permits others to distribute, remix, adapt, build upon this work non-commercially, and license their derivative works on different terms, provided the original work is properly cited, appropriate credit is given, any changes made indicated, and the use is non-commercial. See: http://creativecommons.org/licenses/by-nc/4.0/.

ORCID iD

Zhikuan Yang http://orcid.org/0000-0003-4921-6825

\section{REFERENCES}

1 Morgan IG, Ohno-Matsui K, Saw S-M. Myopia. Lancet 2012;379:1739-48.

2 Mutti DO, Zadnik K. Has near Work's StAR fallen?Optom Vis Sci 2009;86:76-8.

3 Huang H-M, Chang DS-T, Wu P-C. The association between near work activities and myopia in Children-A systematic review and meta-analysis. PLoS One 2015;10: e0140419.

4 Rah MJ, Mitchell GL, Mutti DO, et al. Levels of agreement between parents' and children's reports of near work. Ophthalmic Epidemiol 2002;9:191-203.

5 Rah MJ, Mitchell GL, Bullimore MA, et al. Prospective quantification of near work using the experience sampling method. Optom Vis Sci 2001;78:496-502.

6 Williams R, Bakshi S, Ostrin EJ, et al. Continuous objective assessment of near work. Sci Rep 2019;9:6901.

7 French AN, Ashby RS, Morgan IG, et al. Time outdoors and the prevention of myopia. Exp Eye Res 2013;114:58-68.
8 Xiong S, Sankaridurg P, Naduvilath T, et al. Time spent in outdoor activities in relation to myopia prevention and control: a meta-analysis and systematic review. Acta Ophthalmol 2017;95:551-66.

9 Wu P-C, Chen C-T, Lin K-K, et al. Myopia prevention and outdoor light intensity in a school-based cluster randomized trial. Ophthalmology 2018;125:1239-50.

10 He M, Xiang F, Zeng Y, et al. Effect of time spent outdoors at school on the development of myopia among children in China. JAMA 2015;314:1142-8.

11 Wu P-C, Tsai C-L, Wu H-L, et al. Outdoor activity during class recess reduces myopia onset and progression in school children. Ophthalmology 2013;120:1080-5.

12 Karouta C, Ashby RS. Correlation between light levels and the development of deprivation myopia. Invest Ophthalmol Vis Sci 2015;56:299-309.

13 Lan W, Feldkaemper M, Schaeffel F. Intermittent episodes of bright light suppress myopia in the chicken more than continuous bright light. PLoS One 2014;9:e110906.

14 Smith EL, Hung L-F, Huang J. Protective effects of high ambient lighting on the development of form-deprivation myopia in rhesus monkeys. Invest Ophthalmol Vis Sci 2012;53:421-8.

15 Wang $Y$, Ding $H$, Stell WK, et al. Exposure to sunlight reduces the risk of myopia in rhesus monkeys. PLoS One 2015;10:e0127863.

16 Hua W-J, Jin J-X, Wu X-Y, et al. Elevated light levels in schools have a protective effect on myopia. Ophthalmic Physiol Opt 2015;35:252-62.

17 Read SA, Collins MJ, Vincent SJ. Light exposure and eye growth in childhood. Invest Ophthalmol Vis Sci 2015;56:6779-87.

18 Verkicharla PK, Ramamurthy D, Nguyen QD, et al. Development of the FitSight fitness Tracker to increase time outdoors to prevent myopia. Trans/ Vis Sci Technol 2017;6:20.

19 Wen L, Lan W, Huang Y, et al. A novel device to record the behavior related to myopia development-preliminary results in the lab. IOVS 2016;57:ARVO E-Abstract 2491.

20 Mutti DO, Mitchell GL, Moeschberger ML, et al. Parental myopia, near work, school achievement, and children's refractive error. Invest Ophthalmol Vis Sci 2002;43:3633-40.

21 Quek TPL, Chua CG, Chong CS, et al. Prevalence of refractive errors in teenage high school students in Singapore. Oph Phys Optics 2004;24:47-55.

22 Ip JM, Saw S-M, Rose KA, et al. Role of near work in myopia: findings in a sample of Australian school children. Invest Ophthalmol Vis Sci 2008;49:2903-10.

23 SM L, SY L, Kang MT, et al. Near work related parameters and myopia in Chinese children: the Anyang childhood eye study. PLoS One 2015;10:e0134514.

24 Dharani $R$, Lee $C-F$, Theng ZX, et al. Comparison of measurements of time outdoors and light levels as risk factors for myopia in young Singapore children. Eye 2012:26:911-8

25 Morgan IG, French AN, Ashby RS, et al. The epidemics of myopia: aetiology and prevention. Prog Retin Eye Res 2018;62:134-49. 